Check for updates

Cite this: RSC Adv., 2020, 10, 32345

\title{
Bagasse as a carbon structure with high sulfur content for lithium-sulfur batteries $\uparrow$
}

\author{
Jingjing Ma, Li Yang, Xiaoxun Yang, Yuanchao Li, (D) Erqing Zhao, Shumin Fan, \\ Guangri Xu, (D) Tianjun Lou and Hongying Niu (DD*
}

\begin{abstract}
A bagasse-based 3D carbon matrix ( $\mathrm{BC}$ ) with high specific surface area and high conductivity was obtained by carbonization and pore-forming processes with bagasse as the carbon precursor and $\mathrm{K}_{2} \mathrm{FeO}_{4}$ as the pore-former. The microporous structure and nitrogenous functional groups were determined in the prepared carbon matrix, which could allow high sulfur loading and improve the polysulfide absorption capacity during cycling. After sulfur infusion, the S/BC composite with $68.8 \%$ sulfur content was obtained. The lithium-sulfur ( $\mathrm{Li}-\mathrm{S}$ ) battery with the S/BC cathode shows high specific capacity and good cycling performance. It delivers a specific capacity of $1360 \mathrm{~mA} \mathrm{~h} \mathrm{~g}^{-1}$ at $0.2 \mathrm{C}$ and remains at $790 \mathrm{~mA} \mathrm{~h} \mathrm{~g}^{-1}$ after 200 cycles. At 1C, the Li-S with this composite cathode exhibits $601 \mathrm{~mA} \mathrm{~h} \mathrm{~g}^{-1}$ after 150 cycles. This work offers a new kind of green material and a new method for Li-S batteries.
\end{abstract}

Received 16th February 2020 Accepted 24th August 2020

DOI: $10.1039 / \mathrm{dOra01485 \textrm {k }}$

rsc.li/rsc-advances elements could effectively reduce the shuttle action of polysulfide. ${ }^{28}$ The production of bagasse is enormous. It is suitable used to prepare the $3 \mathrm{D}$ porous carbon matrix (BC) for the $\mathrm{Li}-\mathrm{S}$ battery. In addition, the bagasse is cheap and environmentally friendly.

\section{Materials and methods}

\section{Preparation of porous bagasse carbon}

The bagasse was got from a sugar refinery in Xinxiang, China. The bagasse was first shredded and washed with purified water to remove impurities. Then the bagasse was dipped into $1 \mathrm{M}$ $\mathrm{H}_{2} \mathrm{SO}_{4}$ solution for $24 \mathrm{~h}$ and dried at $80{ }^{\circ} \mathrm{C}$ to remove the water. After that, the sample was heated at $400{ }^{\circ} \mathrm{C}$ for $2 \mathrm{~h}$ at the heating rate of $5{ }^{\circ} \mathrm{C} \mathrm{min}^{-1}$ under nitrogen atmosphere to get bagasse carbon. $\mathrm{K}_{2} \mathrm{FeO}_{4}$ powder was dissolved in pure water and obtained a solution of $0.04 \mathrm{M}$ concentration. Then the prepared bagasse carbon $(0.5 \mathrm{~g})$ was added into the solution under stirring. After $8 \mathrm{~h}$, this sample was dried at $80{ }^{\circ} \mathrm{C}$ to remove the water. The dried material was heated at $800{ }^{\circ} \mathrm{C}$ for $2 \mathrm{~h}$ with heating rate of $5{ }^{\circ} \mathrm{C} \mathrm{min}^{-1}$ in a tube furnace under nitrogen atmosphere. The cooled material was washed several times with dilute hydrochloric acid and purified water and dried to obtain bagasse-based porous carbon matrix (BC).

\section{Preparation of $\mathrm{S} / \mathrm{BC}$ composite}

The porous $\mathrm{BC}$ and sulfur were mixed evenly with a mass ratio of $1: 5$ using ball milling method. The mixture was heated at $155^{\circ} \mathrm{C}$ for $20 \mathrm{~h}$ with the heating rate of $0.5^{\circ} \mathrm{C} \mathrm{min}{ }^{-1}$, and next in the heating rate of $5{ }^{\circ} \mathrm{C} \min ^{-1}$ up to $300{ }^{\circ} \mathrm{C}$ and keep for $2 \mathrm{~h}$ under nitrogen atmosphere. After cooling, the S/BC was obtained. For comparison, carbon nanotubes (CNT) and sulfur
College of Chemistry and Chemical Engineering, Henan Institute of Science and Technology, Xinxiang, 453003, P. R. China. E-mail: hongying_niu1974@163.com

$\dagger$ Electronic supplementary information (ESI) available. See DOI: 10.1039/d0ra01485k 
elements were mixed at the same mass ratio. After a series of the same steps described above, the S/CNT composite material was obtained.

\section{Material characterization}

The scanning electron microscopy (SEM) was recorded on a field emission SEM (Nova NanoSEM 450, FEI Company, USA). Fourier transform infrared (FTIR) spectra was measured by a Paragon 1000 spectrophotometer (PerkinElmer, Inc US). Raman spectrometry was performed using a Raman spectrometer (DXR, Thermo Fisher Scientific Inc., USA) with a laser wavelength of $532 \mathrm{~nm}$ at room temperature. The structure of the composite was tested by powder X-ray diffraction (D8 Advance, Bruker Corp., Germany, XRD) using $\mathrm{Cu}-\mathrm{K} \alpha$ radiation at $40 \mathrm{kV}$. Electrical conductivity was done by the method of four-point probe (DP-SB100A/20, Beijing Ya'ou De Peng Technology Co. Ltd., China). Specific surface area and aperture distribution of the composites was performed by specific surface analyzer (ASAP 2010M + C, Micromeritics, USA).

\section{Electrochemical measurements}

S/BC or S/CNT composite, Super-P and CMC were mixed with the mass ratio of $8: 1: 1$ to homogeneous slurry and coated onto the aluminum foil and dried in a vacuum oven at $60{ }^{\circ} \mathrm{C}$ to fabricate working electrodes. The sulfur loading of the cathode was $1 \mathrm{mg} \mathrm{cm}^{-2}$. The coin cells were assembled in an argon-filled glove box (Mbraun, $\mathrm{H}_{2} \mathrm{O}, \mathrm{O}_{2}<0.1 \mathrm{ppm}$ ) with $1 \mathrm{M} \mathrm{Li}$ bis(trifluoromethane-sulfonamide)imide (LiTFSI) and $2 \mathrm{wt} \%$ $\mathrm{LiNO}_{3}$ in 1,3-dioxolane (DOL)/1,2-dimethoxyethane solvent (DME) (1:1, by volume) as electrolyte, Celgard 2400 as separator and Li foil (Alfa Aesar) as anode. The charge-discharge was tested by Land CT2001A multi-channel battery testing system within the voltage range from $1.7 \mathrm{~V}$ to $2.8 \mathrm{~V}\left(v s\right.$. $\left.\mathrm{Li} / \mathrm{Li}^{+}\right)$at room temperature. The rate performance was tested by the same testing system. Cyclic voltammetry (CV) was tested at the scan rate of $0.2 \mathrm{mV} \mathrm{s}^{-1}$ and the electrochemical impedance spectroscopy (EIS) was recorded within the frequency from $100 \mathrm{kHz}$ to $0.1 \mathrm{~Hz}$ by CHI 660 Electrochemical Work Station (Shanghai Chenhua Group, China).

\section{Results and discussion}

Fig. 1 shows the preparation of S/BC composite materials. In general, the porous carbon was prepared from bagasse and then heated with sulfur to get the cathode material. As the precursor, the bagasse was treated to make pores. After carbonized, the bagasse-based porous carbon matrix with high specific surface area was obtained. Through the test result of the nitrogen adsorption-desorption isotherms, the porous carbon matrix displays a isotherms of BET surface area of $793.4 \mathrm{~m}^{2} \mathrm{~g}^{-1}$ (Fig. 2A), which is much higher than that of the CNT $\left(362.9 \mathrm{~m}^{2}\right.$ $\mathrm{g}^{-1}$, Fig. S1 $\left.\mathrm{A}^{\dagger}\right)$. The pore size of this porous carbon matrix is 1.7-2 nm calculated by DFT method (Fig. 2B) and $0.5 \mathrm{~nm}$ calculated by Horvath-Kawazoe (H-K) method (Fig. 2C). In addition, the CNT has a pore size of 1-2 $\mathrm{nm}$ (calculated by DFT

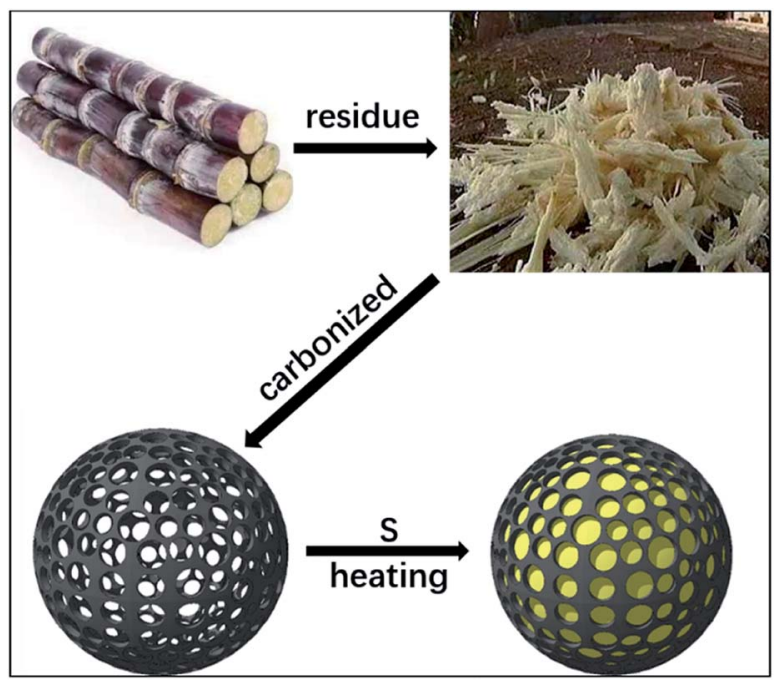

Fig. 1 The preparation process of S/BC composite.
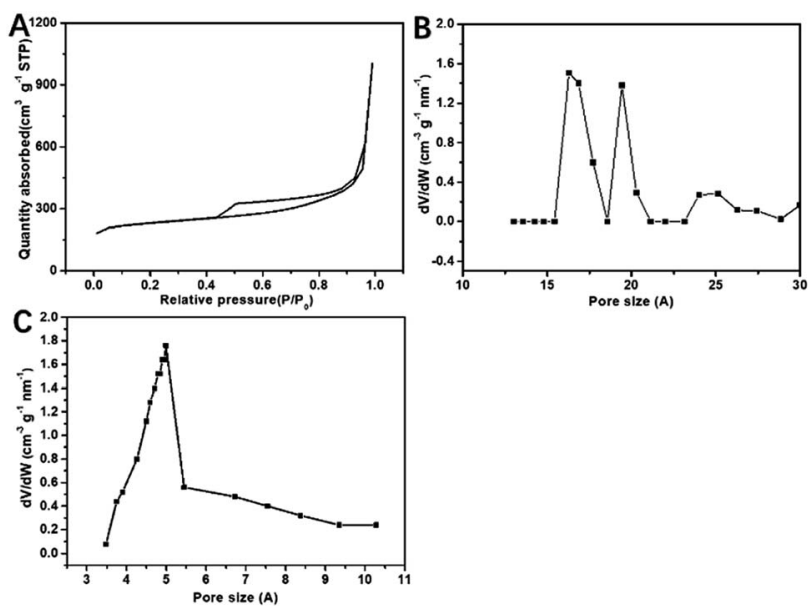

Fig. $2 \mathrm{~N}_{2}$ adsorption/desorption isotherms of S/BC (A); pore size distribution plots calculated by $\mathrm{H}-\mathrm{K}(\mathrm{B})$ and DFT of $\mathrm{S} / \mathrm{BC}(\mathrm{C})$.

method, Fig. $\mathrm{S} 1 \mathrm{~B} \dagger$ ) and $0.9 \mathrm{~nm}$ (calculated by $\mathrm{H}-\mathrm{K}$ method, Fig. $\mathrm{S} 1 \mathrm{C} \dagger)$.

The SEM images of BC and S/BC samples are shown in Fig. 3. The BC sample contains many pores which could provide space for sulfur loading and $\mathrm{Li}^{+}$diffusion/transport (Fig. 3A and B). After mixed with the sulfur and heating, the pores were filled with the sulfur (Fig. 3C and D). As a result, the S/BC composite was obtained. In addition, energy-dispersive X-ray spectroscopy (EDS) analysis shows homogeneous distribution of $\mathrm{S}$ and $\mathrm{C}$ elements throughout the S/BC composite (Fig. S2 $\dagger$ ), suggesting the sulfur loaded within the $\mathrm{BC}$ matrix rather than aggregated on the surface.

X-ray diffraction (XRD) patterns of S/CNT, S/BC and S are shown in Fig. 4A. In Fig. $4 \mathrm{~A}$, the peaks of sulfur at $23^{\circ}, 25^{\circ}$ and $28^{\circ}$ still remained in the XRD peaks of S/BC and S/CNT, suggesting that the sulfur is present in long chains. In Fig. 4B, FTIR spectrum peaks at $1795 \mathrm{~cm}^{-1}$ and $1257 \mathrm{~cm}^{-1}$ in the S/BC 

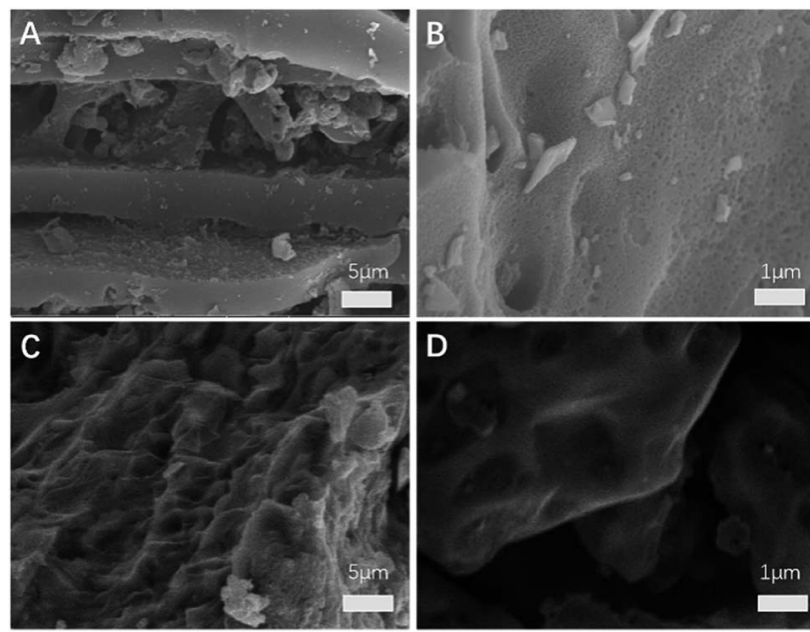

Fig. 3 SEM images of $B C(A$ and $B)$ and S/BC (C and $D)$.
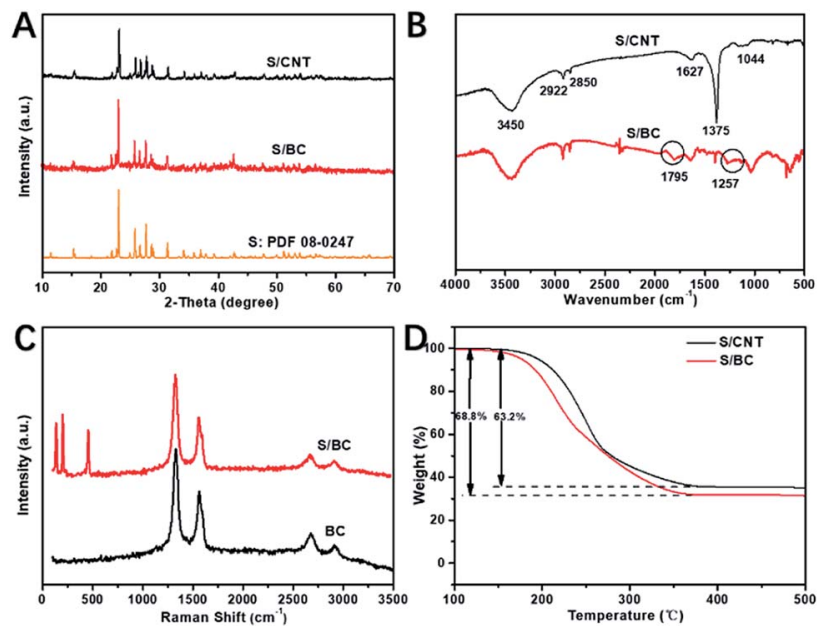

Fig. 4 XRD patterns of S/CNT, S/BC and S (A); FTIR spectrum of S/BC and S/CNT (B); Raman spectra of BC and S/BC (C); TGA of S/BC and S/ CNT (D).

represent the vibration strengths of $\mathrm{C}=\mathrm{N}$ and $\mathrm{C}-\mathrm{N}$, respectively, which could not been found in the FTIR spectrum of S/CNT. It means the $\mathrm{S} / \mathrm{BC}$ has the $\mathrm{N}$ element. As a result, these groups would have great effects on absorbing polysulfides. Fig. 4C shows the Raman spectra of $\mathrm{BC}$ and S/BC. Two peaks at $2700 \mathrm{~cm}^{-1}$ and $2900 \mathrm{~cm}^{-1}$ are due to the presence of graphitized carbon, while the peaks at $500 \mathrm{~cm}^{-1}, 250 \mathrm{~cm}^{-1}$ and $200 \mathrm{~cm}^{-1}$ stand for sulfur. To make a comparison, the Raman spectra of CNT and S/CNT (Fig. S3†) composite were determined. The characteristic peaks mentioned above also appear in it. The graphitic carbon could improve the electron transport. Through four-point technique test, the electronic conductivity of $\mathrm{S} / \mathrm{BC}$ is $0.83 \mathrm{~S} \mathrm{~cm}^{-1}$, and it is higher than some other $\mathrm{S} /$ porous carbon composites including S/CNT prepared in this paper $\left(0.14 \mathrm{~S} \mathrm{~cm}^{-1}\right)$. The theoretical maximum sulfur capacity is $74.4 \mathrm{wt} \%$, which is based on the density of liquid sulfur $\left(1.82 \mathrm{~g} \mathrm{~cm}^{-3}\right)$ and the volume of pore $\left(1.6 \mathrm{~cm}^{3} \mathrm{~g}^{-1}\right)$. The content of sulfur in the S/BC and S/CNT composite was $68.8 \%$ and $63.2 \%$, respectively by thermogravimetric analysis (TGA) test (Fig. 4D).

Cyclic voltammograms (CVs) was used to study the kinetic process of $\mathrm{S} / \mathrm{BC}$ and $\mathrm{S} /$ carbon nanotubes (S/CNT) cathode composites during charge and discharge. Fig. 5A and B show that the S/BC battery has better peak consistency than the S/ CNT battery, indicating the S/BC battery has good cycle stability, which is due to the structure and functional groups of cathode composites in the S/BC battery. Both of these two batteries have two reduction peaks corresponding to the stepwise reduction from $\mathrm{S}_{8}$ to long chain ordered polysulfides $\left(\mathrm{Li}_{2} \mathrm{~S}_{y}\right.$, $4 \leq y \leq 8)$ and further to insoluble $\mathrm{Li}_{2} \mathrm{~S}_{2} / \mathrm{Li}_{2} \mathrm{~S}$. The oxidation peak at 2.35-2.45 $\mathrm{V}$ represents the reversible conversion of lithium sulfide to metallic $\mathrm{Li}$ and $\mathrm{S}_{8}$. The electrochemical cycling performances of the S/BC battery and the S/CNT battery at $0.2 \mathrm{C}$ (Fig. 5C) and $1 \mathrm{C}$ (Fig. 5D) were evaluated. In the initial cycle, the S/BC exhibits a high discharge capacity of $1360 \mathrm{~mA} \mathrm{~h} \mathrm{~g}{ }^{-1}$, and while after 200 cycles, it remains $790 \mathrm{~mA} \mathrm{~h} \mathrm{~g}^{-1}$ at $0.2 \mathrm{C}$, which shows good cycle stability. On the contrary, the S/CNT battery demonstrates a low specific capacity (1048 $\mathrm{mA} \mathrm{h} \mathrm{g}^{-1}, 1^{\text {st }}$ cycle) and a rapid capacity attenuation during the cycling $\left(381 \mathrm{~mA} \mathrm{~h} \mathrm{~g}^{-1}, 200^{\text {th }}\right.$ cycle) when compared with the S/BC battery (Fig. $5 \mathrm{E}$ and $\mathrm{F}$ ). At a higher rate, $1 \mathrm{C}$, the $\mathrm{S} /$ $\mathrm{BC}$ battery also displays better electrochemical performance
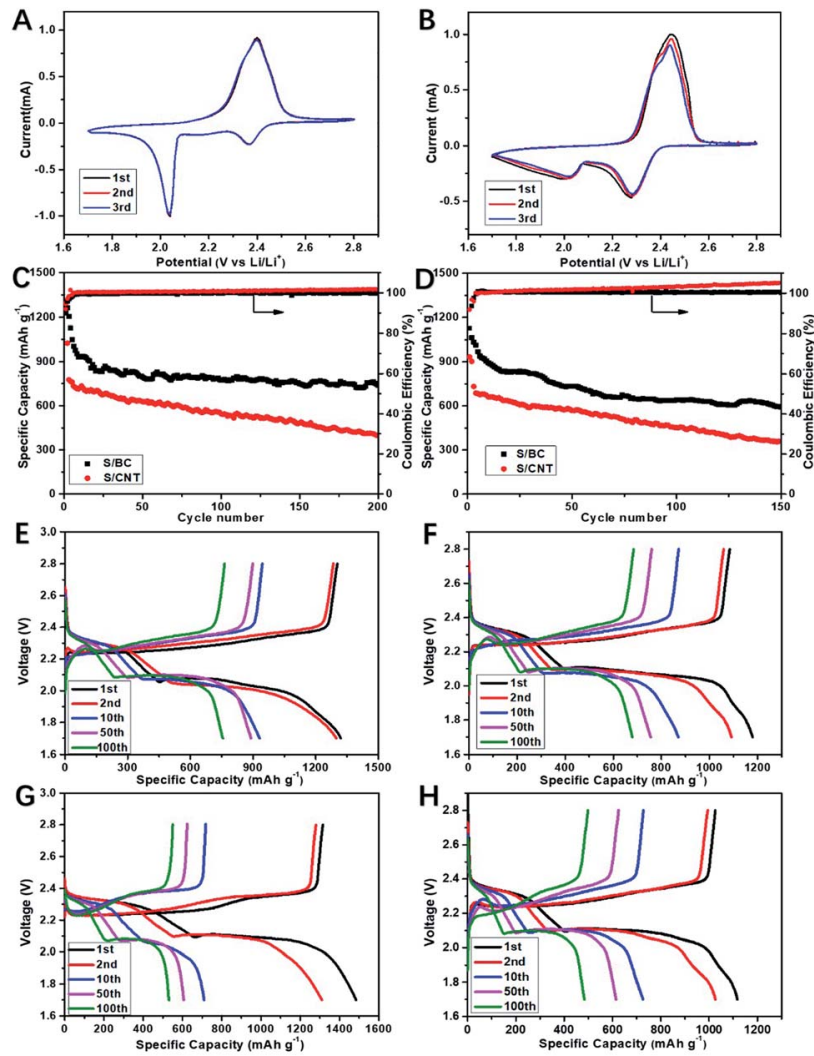

Fig. 5 Cyclic voltammograms of the S/BC cell (A) and S/CNT cell (B); cycling performance of the S/BC cell and S/CNT cell at $0.2 C(C)$ and $1 C$ (D); discharge/charge profiles of the S/BC cell and S/CNT at $0.2 \mathrm{C}$ (E and $\mathrm{F}$ ) and at $1 \mathrm{C}(\mathrm{G}$ and $\mathrm{H})$. 
than the S/CNT cell (Fig. 5G and H). The coulombic efficiency of S/BC keeps a high stability near $100 \%$ during the cycling. For the S/CNT battery, it exceeds 100 percent and increases gradually because of the shuttle effect of lithium polysulfides. The results show that the bagasse-based porous carbon matrix could reduce polysulfide shuttle effectively due to its high electronic conductivity $\left(8.2 \mathrm{~S} \mathrm{~cm}^{-1}\right)$, porous structure and nitrogenous functional groups. Therefore the $\mathrm{S} / \mathrm{BC}$ battery has better cycling performance than the S/CNT cell. Compared with the various carbon derived from natural materials for Li-S battery applications published recently (Table S1†), the cathode material S/ BC synthesised in this work has advantages in reversible specific capacity and capacity retention. Rate performance profiles at different rate are shown in Fig. 6A. The discharge capacity is determined to be $1096 \mathrm{~mA} \mathrm{~h} \mathrm{~g}{ }^{-1}, 870 \mathrm{~mA} \mathrm{~h} \mathrm{~g}{ }^{-1}$, $689 \mathrm{~mA} \mathrm{~h} \mathrm{~g}^{-1}$, and $555 \mathrm{~mA} \mathrm{~h} \mathrm{~g}^{-1}$ at $0.1,0.5,1$ and 2C, respectively. Both S/BC and S/CNT cells indicate discharge capacity reduction when the discharge rate increases from $0.1 \mathrm{C}$ to $2 \mathrm{C}$. The capacity recovery of $\mathrm{S} / \mathrm{BC}$ is better than that of $\mathrm{S} / \mathrm{CNT}$ when the discharge rate returned from $2 \mathrm{C}$ to $0.1 \mathrm{C}$ (Fig. $6 \mathrm{~B}$ and $\mathrm{C}$ ). The high rate capacity of $\mathrm{S} / \mathrm{BC}$ is still the result of the porous structure, high electronic conductivity and groups in the cathode.

Electrochemical impedance spectroscopy (EIS) was measured to the change of electrode before and after circulation. The Nyquist plots of the S/BC cell and S/CNT cell at fully charged after different cycles are shown in Fig. 6D. From high frequency to middle, the plots display as a single semicircle, and in the low frequency region, it becomes a slope line, which represents interfacial charge transfer and lithium ion diffusion, respectively. The high frequency intercept represents the resistance of the battery, while the length between the high and low frequency intercepts represents the electrode polarization resistance. The Nyquist plots and equivalent circuits are consisted of the bulk resistance of the electrolyte $\left(R_{\mathrm{e}}\right)$, charge transfer resistance $\left(R_{\mathrm{c}}\right)$, constant phase element (CPE) and Warburg impedance $(W)$. As shown in Table $\mathrm{S} 2, \uparrow$ no matter at $1^{\text {st }}$

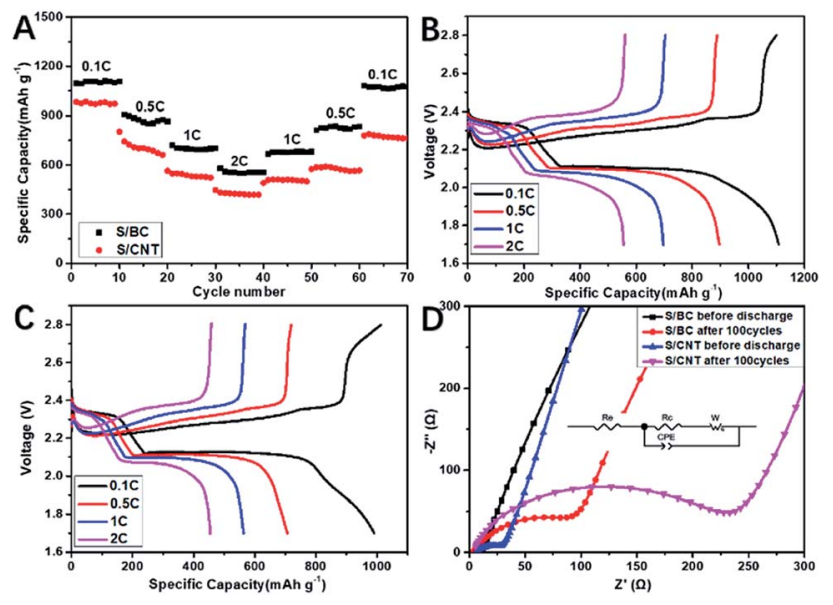

Fig. 6 Rate performance of the S/BC cell and S/CNT cell (A); discharge/charge profiles of the S/BC (B) and S/CNT (C) at different current densities; EIS plots of the S/BC cell and S/CNT cell after different cycles at $0.2 C$ (D). or $100^{\text {th }}$ cycle, the $R_{\mathrm{c}}$ for $\mathrm{S} / \mathrm{BC}$, the cell resistance and polarization resistance of $\mathrm{S} / \mathrm{BC}$ batteries are both smaller than those of $\mathrm{S} / \mathrm{CNT}$ batteries. This is due to the special structure of the bagasse-based porous carbon matrix.

\section{Conclusions}

A 3D carbon matrix has been prepared using bagasse as carbon precursor and $\mathrm{K}_{2} \mathrm{FeO}_{4}$ as pore-former. The bagasse-based carbon (BC) possesses high specific surface area $\left(793.4 \mathrm{~m}^{2} \mathrm{~g}^{-1}\right)$, high conductivity $\left(8.2 \mathrm{~S} \mathrm{~cm}^{-1}\right)$, abundant micro pores (pore width $<2 \mathrm{~nm}$, pore volume $1.6 \mathrm{~cm}^{3} \mathrm{~g}^{-1}$ ) and nitrogenous functional groups, which make it a good carbon host for sulfur loading. Among them, the porous structure and nitrogenous functional groups in BC could allow high sulfur loading and effectively inhibit lithium polysulfide shuttle. As a result, the S/BC cathode composite with $68.8 \%$ sulfur content was obtained and exhibits superior long-term cycling stability and rate performance in $\mathrm{S} / \mathrm{BC} \mid \mathrm{Li}$ full cell. It delivers high specific capacity of $1360 \mathrm{~mA} \mathrm{~h} \mathrm{~g}^{-1}$ at $0.2 \mathrm{C}$ in the initial cycle and remains $790 \mathrm{~mA} \mathrm{~h} \mathrm{~g}^{-1}$ after 200 cycles with a stable coulombic efficiency near $100 \%$ during cycling. At $1 \mathrm{C}$, the $\mathrm{Li}-\mathrm{S}$ with this composite cathode exhibits $601 \mathrm{~mA} \mathrm{~h} \mathrm{~g}{ }^{-1}$ after 150 cycles. This work provides a good idea for the preparation of low cost and green Li-S battery.

\section{Conflicts of interest}

There are no conflicts to declare.

\section{Acknowledgements}

We are grateful for the financial support from the National Natural Science Foundation of China (21703057), the Henan Postdoctoral Science Foundation (1902040, 00182023), the Foundation of Henan Education Committee (16A150008, 17A150027), and the Programs for Science and Technology Development of Henan province (202102210107, 192102210016, 192102310249).

\section{References}

1 J. M. Tarascon and M. Armand, Nature, 2001, 414, 359-367.

2 B. Dunn, H. Kamath and J. M. Tarascon, Science, 2011, 334, 928-935.

3 C. Ye, Y. Jiao and H. Jin, Angew. Chem., Int. Ed., 2018, 57, 16703-16707.

4 N. S. Choi, Z. Chen and S. A. Freunberger, Angew. Chem., Int. Ed., 2012, 51, 9994-10024.

5 A. Manthiram, Y. Fu and Y. S. Su, Acc. Chem. Res., 2012, 46, 1125-1134.

6 K. Zhang, Q. Zhao and Z. Tao, Nano Res., 2013, 6, 38-46.

7 H. Wang, Y. Yang and Y. Liang, Nano Lett., 2011, 11, 26442647.

8 J. Zhang, N. Yang and X. Yang, J. Alloys Compd., 2015, 650, 604-609. 
9 H. Zhao, Z. Peng and W. Wang, J. Power Sources, 2014, 245, 529-536.

10 D. W. Wang, G. Zhou and F. Li, Phys. Chem. Chem. Phys., 2012, 14, 8703-8710.

11 M. Weinberger, J. Munding and M. Lindén, Energy Technol., 2018, 6, 1797-1804.

12 J. Schuster, G. He and B. Mandlmeier, Angew. Chem., Int. Ed., 2012, 51, 3591-3595.

13 C. Zhang, H. B. Wu and C. Yuan, Angew. Chem., Int. Ed., 2012, 51, 9592-9595.

14 J. Guo, Y. Xu and C. Wang, Nano Lett., 2011, 11, 4288-4294.

15 S. Moon, Y. H. Jung and W. K. Jung, Adv. Mater., 2013, 25, 6547-6553.

16 R. Elazari, G. Salitra and A. Garsuch, Adv. Mater., 2011, 23, 5641-5644.

17 R. Fang, S. Zhao and P. Hou, Adv. Mater., 2016, 28, 33743382.

18 C. Wang, W. Wan and J. T. Chen, J. Mater. Chem. A, 2013, 1, 1716-1723.
19 Z. W. Seh, W. Li and J. J. Cha, Nat. Commun., 2013, 4, 13311336.

20 A. Manthiram, Y. Fu and S. H. Chung, Chem. Rev., 2014, 114, 11751.

21 Z. Li, L. Yuan and Z. Yi, Adv. Energy Mater., 2014, 4, 1301473. 22 H. J. Peng, G. Zhang and X. Chen, Angew. Chem., 2016, 128, 13184-13189.

23 Y. Zhong, X. Xia and S. Deng, Adv. Energy Mater., 2018, 8, 1701110.

24 J. Zhou, Y. Guo and C. Liang, Electrochim. Acta, 2018, 273, 127-135.

25 L. Bao and X. Li, Adv. Mater., 2012, 24, 3246-3252.

26 Z. Gao, Y. Zhang and N. Song, Electrochim. Acta, 2017, 246, 507-516.

27 S. Song, Y. He and Y. Ruan, Mater. Lett., 2019, 247, 86-89.

28 T. Z. Hou, X. Chen and H. J. Peng, Small, 2016, 12, 32833291. 